DOI 10.18551/rjoas.2019-01.19

\title{
NATIONAL SECURITY OF INVESTMENT CLIMATE: A CASE STUDY IN THE SOUTH SULAWESI REGION OF INDONESIA
}

\author{
Siswanto Dwi Joko \\ Social and Political Science Program, University of Padjadjaran, Indonesia \\ Tegor \\ Graduate Program In Management, University of Esa Unggul, Indonesia \\ *E-mail: dwijokos2000@gmail.com \\ ORCID: 0000-0001-9343-8025
}

\begin{abstract}
A safe area is certainly not a guarantee that the investment climate will be high. Consumer confidence in investing is one of the factors that can mediate an increase in the investment climate of a region. This study aims to: (1) determine the effect of national security on the regional investment climate, (2) find out the effect of national security on the consumer confidence index, (3) find out the effect of national security on the regional investment climate mediated by consumer confidence index. This study applied the analysis of Structural Equation Model (SEM). The findings showed that national security has a direct effect on the investment climate with a value of $t=3.07(>1.96)$. Moreover, the correlation between national security and consumer confidence index is significant with a value of $t=4.35$ $(>1.96)$. Next, the correlation between consumer confidence index and investment climate is also significant, with a value of $t=2.51(>1.96)$. The level of security of a Regency/ City in South Sulawesi reflects the absence of a sense of fear and anxiety about the possibility of threats to the soul, property, and honor. If an area is considered safe, it will increase the investment climate because investors will invest in safe and remote areas of conflict. Therefore, it will not disrupt their business process.
\end{abstract}

\section{KEY WORDS}

National security, consumer confidence index, investment climate, crime rate, crime clock, crime clearance, crime index.

A sense of security is one of the main needs for people's lives that must be fulfilled. Talking about people's welfare, it is inseparable from the aspect of security (Huitt, 2004). The government cannot say that its people have prospered while their daily lives they are disturbed by a sense of fear and anxiety about the possibility of threats to their soul, property, and honor. Maslow places the need for safety on the second level after physiological needs including eating and drinking, from five levels of needs (McLeod, 2007).

The Central Bureau of Statistics of South Sulawesi Province has developed a safety measure as a way to study the factors of security components. The measuring instrument is processed based on the existing secondary data and survey results in the field. This was conducted because the factors affecting security vary greatly in type and amount making it difficult to judge.

A stable and conducive condition will create a sustainable investment realization in the South Sulawesi region. The conducive investment climate in the economy is a hope for the community, investors, business people and the government in the South Sulawesi region. Continuous efforts made by bureaucrats and economic actors in South Sulawesi are to: (1) provide legal certainty over regional regulations and legal products relating to investment activities so that they do not provide additional burden on business production costs, (2) maintain security from potential criminal interference by unscrupulous people against the company's valuable assets, on goods and warehouse distribution channels, and on places 
for storing finished and intermediate goods, (3) provide the most basic for services for investors including investment, immigration, customs, taxation and regional defense licenses.

Indonesia is in the first rank of the highest consumer confidence index with the score of 122 from the 58 countries surveyed by Nielsen Company followed by India (120), Philippines (118), and Thailand (116). This study can assume that the consumer confidence index predicts the direction of public consumption and expectations of price pressures which are then used to estimate the availability of goods and services, production capacity, and realization of output. The level of security in the Indonesian region globally has an effect on the turmoil of public security and order disturbances in the South Sulawesi region. It may have an impact on the value of investments made by investors in investing their capital; especially big investors who need high security guarantees so they can invest for a long time. The current condition occurring in the South Sulawesi region is when the security level is at level 1 (the absence of community fluctuations that can affect the running of the government of South Sulawesi), the investment climate will be at level 8 or in a fresh position for investment size. On the other hand, if the level of security is at level 2 and 3 then the investment climate is in the medium and low position.

One of the conditions or facts that indicate that the investment taking place in South Sulawesi is considered problematic is when Parepare Integrated Economic Zone does not function optimally even though it has been organizationally provided with adequate facilities and support from the government. The Parepare Integrated Economic Zone was established in order to carry out the mission of improving the investment climate in the region. However, the investment climate in South Sulawesi has not developed well as the expectation. Regarding to this matter, it is suspected that the underdeveloped investment climate is affected by economic factors and non-economic factors. Both of these factors each have a fairly fundamental effect on the development of investment in the South Sulawesi region.

\section{METHODS OF RESEARCH}

Research Design. This study is a causal study conducted to detect causal correlation between two or more variables (Bax et al, 2006). In this study, researchers want to know the effect of national security on the investment climate in the district and find out whether the effect is moderated by the consumer confidence index. This study is a quantitative research and the data obtained are secondary data.

Population and Samples. The population of the study is middle to upper society and domestic and foreign investors in 21 districts and 3 cities of the population which are the objects of research that are considered to represent conditions that occur in the population. Determining samples from the population applied the Proportionate Stratified Random Sampling. This technique is used if the population has members/ elements that are not homogeneous and proportionately structured. Determination of this sample was carried out because the data are secondary data. Meanwhile, determining samples from data sources applied the Proportionate Stratified Random Sampling method. Determination of the sample from the population used a reference table developed by the experts, one of which is according to Hair et al (2015) who mentioned that the number of samples $=$ number of indicators $\times 5=n \times 5$. Therefore, the number of indicator questions is $15 \times 5=75$ in which the minimum number of respondents is $5 x$ the number of the observation parameters.

Data Analysis Method. Testing of the research model was carried out using Structural Equation Modeling (SEM), also known as Analysis of Moment Structures. This statistical analysis is used to estimate several separate but simultaneously related regressions. In contrast to regression analysis, SEM can have several dependent variables in which this dependent variable can be an independent variable for other dependent variables (Hair et al, 2015). SEM is a multivariate statistical technique that combines aspects of multiple regression (which aims to test dependent relationships) and factor analysis (which presents unified concepts factors with multiple variables) that can be used to estimate a series of dependent correlations that affect each other simultaneously (Bowen \& Guo, 2011). 
The data processing technique of Structural Equation Modeling (SEM) using Confirmatory Factor Analysis (CFA) method were used in this study. Observed variables (indicators) describe a certain latent variable (latent dimension) (Schreiber et al, 2006). As a testing method that combines factor analysis, path analysis and regression. SEM is more of a confirmatory method than an explanatory one in which it aims to evaluate the proposed dimensions from previous studies. By this understanding, SEM can be used as a tool to confirm the pre-knowledge that has been obtained previously. The approach taken to estimate the parameters of the SEM model is divided into 2, consisting of: Structural Model and CFA (Confirmatory Factor Analysis) as the measurement model (Thompson, 2004).

The validity of the indicators used to measure the construct of the measurement model can be seen from the numbers of data processing using LISREL 8.72. The indicator used must have a $t$ value greater than 1.6 and the standardized factor value greater or equal to 0.5 . Meanwhile, the composite reliability of construct variables from the measurement model can be seen from the construct reliability and extracted variance. The construct reliability is good if the value of the reliability construct is $>0.7$ and the value of variance extracted is $>0.5$. The following are the construct reliability and variance extracted equations proposed by Fornel and Laker (1981):

$$
\begin{gathered}
\text { Construct reliability }=\left[(\Sigma \text { std. loading })^{2}\right] /\left[(\Sigma \text { std.loading })^{2}+\Sigma \varepsilon j\right] \\
\text { Variance extracted }=\Sigma \text { std. } \text { loading }^{2} /\left[\Sigma \text { std. loading }{ }^{2}+\Sigma \varepsilon j\right]
\end{gathered}
$$

Structural model compatibility tests are used to test the correlation model between dimensions or variables. Criteria that can be used to test the compatibility of structural models include:

This chi-square value shows deviations between the sample covariance matrix and the fitted (model) covariance matrix. However, this chi-square value will only be valid if the assumption of data normality is met and the sample size is large (Hair et al, 2015). Chisquare is a measure of the poor compatibility of a model where the higher the chi-square value means that the suitability of the model is bad. Meanwhile, the chi-square value of 0 indicates that the model has a perfect match. The ratio of chi-square values, with the degrees of freedom from the model (normed chi-square) and the ratio between $1-3$, are considered to have the appropriate values. In addition, a value of more than 5 is considered poor fit of the model (Lancaster \& Seneta, 2005).

The $P$ value indicates the probability of obtaining a large deviation as indicated by the chi-square value, so that a significant chi-square value (smaller than ó) indicates that the empirical data obtained has a difference with the theory built on SEM. On the other hand, the insignificant probability value is the expected value because it shows that the empirical data is in accordance with the model.

However, the probability of chi-square has a fundamental validity problem in which the discrepancy between theory and data is strongly affected by the size of the sample. If the sample size is small, the data is significantly not different from the theory. Meanwhile, if the sample size is large, the chi-square test will show that the data is significantly different from the theory.

RMSEA measures the deviation of parameter values in a model with a population covariance matrix. In other words, RMSEA is an indicator of the measurement of the compatibility of the most informative model. The RMSEA value below 0.05 indicates the best match and the RMSEA value around 0.08 is an acceptable value (Browne \& Cudeck, 1992). Meanwhile, the RMSEA value of more than 0.1 is considered not to contain a model match (Kelley \& Lai, 2011).

Confidence intervals are used to assess the accuracy of the RMSEA estimation (Steiger, 1990) in which the smaller the distance evidence interval shows a good estimate. Meanwhile, the P-value for test of close fit (RMSEA $<0.05)$ which indicates the probability of proximity of the model match must be greater than 0.05 .

ECVI measures deviations between fitted (model) covariance matrix in analyzed samples and covariance matrix that will be obtained in other samples that have the same 
sample size. ECVI is used to assess the tendency that a single sample model can be crossvalidated at the same sample size and population. The model that has the lowest ECVI shows that it has the potential to be replicated. The ECVI model value, which is slightly lower than the ECVI saturated model and much lower than the independence model, indicates a good fit of the model (Jöreskog, K. G., \& Sörbom, 2003).

AIC and CAIC are used to assess parsimony problems in assessing model compatibility. The AIC and CAIC values are not sensitive to the complexity of the model, but AIC is more sensitive to the number of samples. In addition, CAIC is not sensitive to sample size. AIC and CAIC are used in comparison of two or more models. The AIC and CAIC model values, which are slightly smaller than AIC and CAIC saturated and are much smaller than AIC and CAIC independence, show a good compatibility model. (Hu and Bentler, 1995).

Normed Fit Index (NFI) is one alternative to determine model compatibility (Bentler and Bonetts, 1980). However, NFI has a tendency to lower the suitability of the model on small sample sizes which then revise this index with the Comparative Fit Index (CFI). NFI and CFI values ranged from 0 and 1 obtained from comparisons between hypothesized and independence models. The model is considered as fit if it has NFI and CFI values above 0.9. Non-Normed Fit Index (NNFI) is used to overcome problems that arise due to the complexity of the model. However, since NNFI is non-normed, the value can be greater than 1 in which it will be difficult to interpret. Incremental Fit Index (IFI) is used to overcome parsimony problems and sample sizes which are related to NFI. In addition, the cut-off limit for IFI is 0.9 .

GFI is a measure of the accuracy of the model in producing the observed covariance matrix. The GFI value ranges from 0 to 1 . However, theoretically, the GFI value can be negative, which is not supposed to happen because the negative GFI value is as the worst model. The model can be categorized as good fit if it has a GFI value greater than 0.9 (Siguaw, 2000).

AGFI has the same goal as GFI but it has adjusted to the effect of the free degree of a model. The model is considered to be good fit if it has an AGFI value above 0.9. The same size as GFI and AGFI is Parsimony Goodness of Fit (PGFI), but PGFI has adjusted the effect of free degrees and data complexity. A good model is those who have PGFI greater than 0.6 (Cheung \& Rensvold, 2002).

Mediating variable analysis is carried out through two approaches which consist of different coefficient and multiplication coefficient. The difference coefficient approach uses the examination method by analyzing with and without involving mediating variables. Meanwhile, the multiplication coefficient approach is carried out by using the Sobel method. The examination method, by conducting two analyzes, involves mediating and analysis variables without involving mediating variables (MacKinnon et al, 2007).

The method of examining the mediation variable with the coefficient difference approach is carried out as follows: (a) examine the direct effect of the independent variable on the dependent variable by involving mediating variables, (b) examine the effect of the independent variable on the dependent variable without involving mediating variable, (c) examine the effect of independent variable on mediating variable, and (d) examine the effect of mediating variable on the dependent variable.

\section{RESULTS OF STUDY}

Results of Factor Validity Test. The first step in model analysis is to examine the program output against the possibility of offending estimates. In accordance with the recommendations of Hair et al (2015), the appropriate observation variables used as indicators of the construct or latent variable must have a factor load greater than 0.5 so that the model used has a goodness of fit. In addition, the factor charge of the t-value must be greater than the critical value (>1.96). Detail information can be seen in the following attachment. Based on the validity analysis, the research contract indicator can be seen in the table below: 
Table 1 - Results of Validity Measurement of Order Construct Indicators

\begin{tabular}{|c|c|c|c|c|}
\hline Indicators & Constructs & Loading Factor & T Values & Description \\
\hline NS_1 & \multirow{5}{*}{ National Security } & 0.82 & 10.82 & ACCEPTED \\
\hline NS_2 & & 0.82 & 10.84 & ACCEPTED \\
\hline NS 3 & & 0.86 & 11.69 & ACCEPTED \\
\hline NS 4 & & 0.66 & 7.99 & ACCEPTED \\
\hline NS_5 & & 0.81 & 10.65 & ACCEPTED \\
\hline $\mathrm{CCl} 1$ & \multirow{6}{*}{ Consumer Confidence Index } & 0.64 & 7.32 & ACCEPTED \\
\hline $\mathrm{CCl} 2$ & & 0.73 & 8.70 & ACCEPTED \\
\hline $\mathrm{CCl}_{3}^{-} 3$ & & 0.66 & 8.16 & ACCEPTED \\
\hline $\mathrm{CCl} 4$ & & 0.70 & 7.53 & ACCEPTED \\
\hline $\mathrm{CCl} 5$ & & 0.49 & 5.26 & REJECTED \\
\hline $\mathrm{CCl} 6$ & & 0.62 & 6.98 & ACCEPTED \\
\hline IC_ 1 & \multirow{4}{*}{ Investment Climate } & 0.75 & 9.04 & ACCEPTED \\
\hline IC_2 & & 0.77 & 9.26 & ACCEPTED \\
\hline IC_3 & & 0.66 & 7.55 & ACCEPTED \\
\hline IC 4 & & 0.76 & 9.16 & ACCEPTED \\
\hline
\end{tabular}

Source: Results of SEM Analysis on Data Analysis Tools.

Results of Construct Reliability Test. Model reliability can be tested using Construct Reliability and Varied Extracted calculations using the following formula:

$$
\begin{aligned}
& \text { Construct reliabilit } y=\frac{\left(\sum \text { std loading }\right)^{2}}{\left(\sum \text { std loading }\right)^{2}+\sum \varepsilon_{j}} \\
& \text { Variance extracted }=\frac{\sum \text { stdloading }^{2}}{\sum \text { stdloading }{ }^{2}+\sum \varepsilon_{j}}
\end{aligned}
$$

\begin{tabular}{|c|c|c|c|}
\hline Group & Indicator & Value & Description \\
\hline 1 & $\begin{array}{l}\text { Degree of Freedom } \\
\text { Chi-square } \\
\text { NCP } \\
\text { Confidence Interval }\end{array}$ & $\begin{array}{c}74 \\
156.2 \\
78.59 .24 \\
47.05 ; 117.91 \\
\end{array}$ & Good Fit \\
\hline 2 & $\begin{array}{c}\text { RMSEA } \\
\text { Confidence Interval } \\
\text { P Value }\end{array}$ & $\begin{array}{c}0.093 \\
0.072 ; 0.11 \\
0.00081\end{array}$ & Close Fit \\
\hline 3 & $\begin{array}{c}\text { ECVI Model } \\
\text { ECVI Saturated } \\
\text { ECVI Independence } \\
\text { Confidence Interval }\end{array}$ & $\begin{array}{c}1.74 \\
1.71 \\
7.67 \\
1.49 ; 2.06\end{array}$ & Good Fit \\
\hline 4 & $\begin{array}{c}\text { AIC Model } \\
\text { AIC Saturated } \\
\text { AIC Independence } \\
\text { CAIC Model } \\
\text { CAIC Saturated }\end{array}$ & $\begin{array}{l}214.59 \\
210.00 \\
943.29 \\
333.02 \\
611.13 \\
\end{array}$ & Good Fit \\
\hline 5 & $\begin{array}{c}\text { NFI } \\
\text { CFI } \\
\text { NNFI } \\
\text { IFI } \\
\text { RFI } \\
\text { PNFI }\end{array}$ & $\begin{array}{l}0.83 \\
0.90 \\
0.88 \\
0.90 \\
0.79 \\
0.67\end{array}$ & Good Fit \\
\hline 6 & Critical N & 83.71 & Marginal Fit \\
\hline 7 & $\begin{array}{c}\text { Standardized RMR } \\
\text { GFI } \\
\text { AGFI } \\
\text { PGFI }\end{array}$ & $\begin{array}{l}0.076 \\
0.85 \\
0.79 \\
0.60 \\
\end{array}$ & Marginal Fit \\
\hline
\end{tabular}

Table 2 - Goodness of Fit Analysis

Source: Results of SEM Analysis on Data Analysis Tools. 
According to Bagozi and $\mathrm{Yi}$, good reliability requirements are those that have reliability constructs $>0.6$ and extracted variance $>0.5$. Ghozali \& Fuad (2005) added that reliability requirements can be seen from only one method. From the calculation above, all constructs have met good reliability requirements i.e. the NS (National Security), CCl (Consumer Confidence Index), and IC (Investment Climate).

Goodness of Fit Analysis of the Entire Models. To determine the goodness of fit of the entire model, there are several criteria that can be used. Referring to the criteria set by Wijanto, the results of the goodness of fit analysis of this research model are as follows in Table 2.

\section{Chi Square:}

- Chi Square $=156.45(P=0.00)$. Chi Square Value: the smaller the model, the more appropriate the theoretical model and sample data (the Chi Square values divided by the values of Degree of Freedom). The ideal value is $<3$ which is included in the category of good fit. The result of the division produces a value of 2.11. It shows closer to good fit because a value smaller than 3 is a good fit;

- $\mathrm{NCP}=78.59$ obtained from $156.45-74$ which shows a discrepancy between $\mathrm{S}$ and $\mathrm{S}$ (q) because a small NCP shows closer to good fit.

Root Mean Square Error of Approximation (RMSEA):

- RMSEA $=0.093$ is categorized to closer to good fit (RMSEA $<0.05$ is close fit, RMSEA $<0.08$ is good fit, $0.08<$ RMSEA $<0.10$ is marginal fit, and RMSEA $>0.10$ poor-fit);

- Confidence intervals are used to assess the performance of the RMSEA estimates. At the output, there is a $90 \%$ confidence interval (between $1.49 ; 2.06$ ) around the RMSEA;

- $\quad$-value of good fit test is RMSEA $<0.05=0.00081$. In this study, the $p$-value is $<0.05$. Expected Cross Validation Index (ECVI):

- ECVI model (1.74) is compared with ECVI saturated model (1.71) and ECVI independence model (7.67);

- ECVI model is slightly smaller than the ECVI saturated model and is much larger than ECVI independence. In other words, the ECVI is saturated model is close fit compared to ECVI independence model. Furthermore, the $90 \%$ confidence interval is $1.49 ; 2.06$ then it is a good fit.

Akaike Information Criterion (AIC) dan Consistent Akaike Information Criterion (CAIC):

- AIC model (214.59) is compared to AIC saturated model (210.00) and AIC independence model (943.29). The AIC model is slightly bigger than the AIC saturated model and the difference is far bigger than the AIC independence model. Therefore, it shows good fit;

- CAIC model (333.02) is far from CAIC saturated model (611.13) and also further from CAIC independence (996.77). Therefore, it shows good fit.

Fit Index:

- $\quad$ The Normed Fit Index (NFI) = 0.83 (below 0.90) indicates marginal fit;

- $\mathrm{CFI}=0.90$ (above 0.90 ) indicates good fit;

- Tucker-Lewis Index or Non-Normed Fit index $(\mathrm{NNFI})=0.88(<0.90)$ (below 0.90) indicates marginal fit;

- Incremental Fit Index (IFI) $=0.90$ (above 0.90) indicates good fit;

- Relative Fit Index $(\mathrm{RFI})=0.79$ (below 0.90 ) indicates marginal fit;

- Parsimonious Normed Fit Index $(\mathrm{PNFI})=0.67$ (above 0.6 ) is used for comparison of models that are closer to good fit.

Critical N:

- Critical $\mathrm{N}(\mathrm{CN})=83.71<200$ model belum mewakili sampel data atau marginal fit. Goodness of Fit:

- Root Mean Square Residual (RMR) is a residual average value that results from fitting between the variance-covariance matrix from the model and variancecovariance matrix from the sample data; 
- Standardized RMR $=0.040$ (below 0.05) indicates good fit;

- Goodness of Fit Index (GFI) $=0.85$ (below 0.90) indicates marginal fit and Adjusted Goodness of Fit Index (AGFI) $=0.79$ (below 0.90 ) indicates marginal fit;

- Parsimony Goodness of Fit Index $(\mathrm{PGFI})=0.60$ is not used in comparison of models while PGFI above 0.6 is used for comparison of models in which it shows sufficient fit.

Based on the analysis in groups 1 to 7 , several tests showed sufficient fit; for example, NCP (Non-Centrality Parameter) and PNFI (Parsimonious Normed Fit Index). However, there are many tests that result sufficient fit. Therefore, it can be concluded that the overall goodness of fit of the model meets the requirements. Furthermore, this study produces a path diagram as shown below:

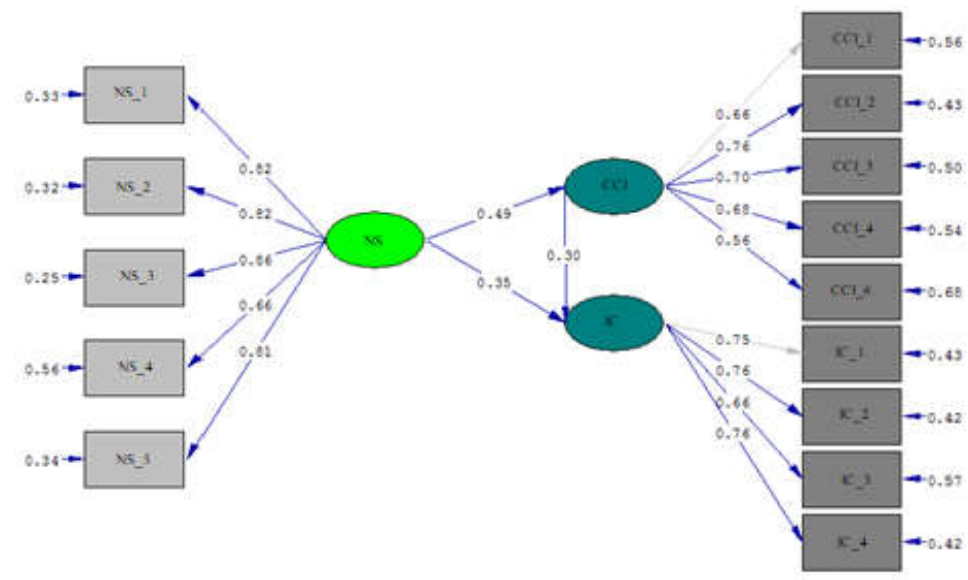

Figure 1 - Path Diagram of Standardized Solution

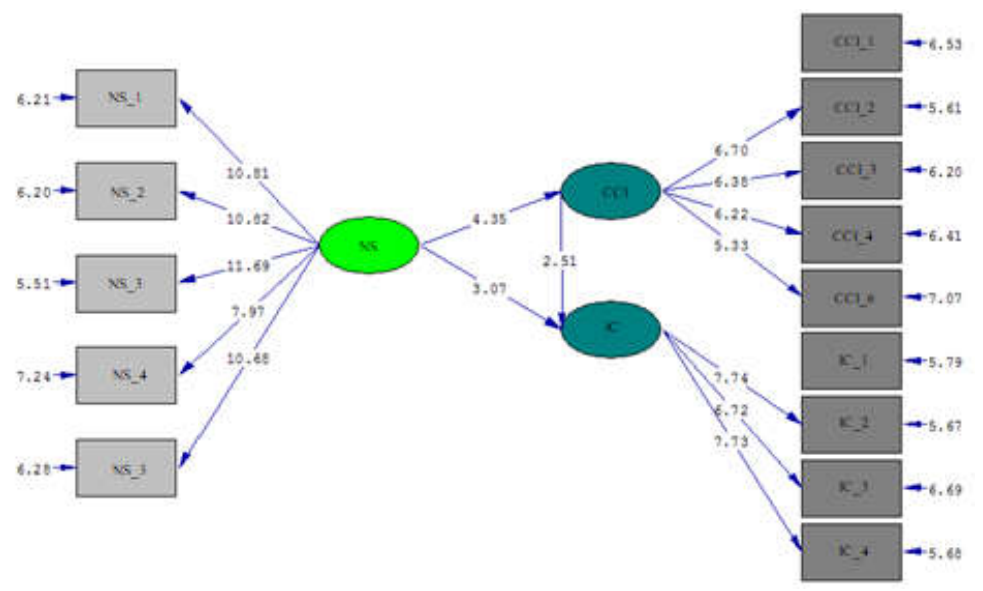

Figure 2 - Path Diagram of T-Value

Results of Hypothesis Testing. In this study, there are five hypotheses. Based on the results of testing, it is concluded that there are three hypotheses which are supported by the data and two hypotheses which are not supported by the data.

Table 4 - Testing of Structural Model Correlation

\begin{tabular}{|c|c|c|c|}
\hline Hypotheses & Hypothesis Statements & T -Value & Description \\
\hline H1 & National Security has positive effect on Consumer & 4.35 & $\begin{array}{c}\text { The data support the } \\
\text { Confidence Index }\end{array}$ \\
\hline H2 & $\begin{array}{c}\text { Consumer Confidence Index has positive effect on } \\
\text { Investment Climate }\end{array}$ & 2.51 & $\begin{array}{c}\text { The data support the } \\
\text { hypothesis }\end{array}$ \\
\hline H3 & National Security has a positive effect on Investment \\
Climate & 3.07 & $\begin{array}{c}\text { The data support the } \\
\text { hypothesis }\end{array}$ \\
\hline
\end{tabular}

Source: Results of SEM Analysis on Data Analysis Tools. 
Results of Mediating Variable Analysis. Mediating variable analysis is carried out through two approaches which consist of different coefficient and multiplication coefficient. The difference coefficient approach uses the examination method by analyzing with and without involving mediating variables. Meanwhile, the multiplication coefficient approach is carried out by using the Sobel method (Hair e al, 2015). Through the coefficient difference method, the results of research hypothesis testing show the effect of the mediating variable of Consumer Confidence Index between the National Security and Investment Climate variables. The mediating variable of the Consumer Confidence Index is used to bridge the correlation between National Security and Investment Climate variables.

Based on the results of testing the coefficient difference on the research model, National Security has a direct effect on Investment Climate with a value of $t=3.07(>1.96)$. Meanwhile, the correlation between National Security and Consumer Confidence Index is significant with a value of $t=4.35(>1.96)$. Moreover, the correlation between the Consumer Confidence Index and Investment Climate is also significant with the value $t=2.51(>1.96)$. Therefore, it can be concluded that the Consumer Confidence Index does not fully mediate the correlation between National Security and Investment Climate. Furthermore, analysis of conclusions, suggestions, and managerial implications will be discussed in more detail in the following sub-headlines.

\section{DISCUSSION OF RESULTS}

The following is a discussion of the research findings that have gone through the process of hypothesis testing and data processing using SEM analysis and LISREL 8.51 analysis tools. The discussion of the research findings is presented as follows:

There is a significant effect of national security in the South Sulawesi region on the consumer confidence index. That is evidenced by the effect of T-Value of 4.35 (>1.96). This shows that the consumer confidence index is directly affected by national security in the South Sulawesi region. The high investment climate in 21 regencies / 3 regions in South Sulawesi shows that the condition of the region is in a safe situation. For investors, security is certainly based on the level of confidence. Therefore, a safe area has an effect on the level of consumer confidence to make an investment.

There is a significant effect of the consumer confidence index on the investment climate. It can be proven from the effect of T-Value of $2.51(>1.96)$. It shows that the investment climate is directly affected by the consumer confidence index. It also shows that the high level of consumer confidence in the South Sulawesi region will produce a positive investment climate in the South Sulawesi region, because public expectations of the development of several economic indicators are very positive. Therefore, South Sulawesi regions with a high level of consumer confidence will provide a positive climate in the economy.

There is a significant effect of South Sulawesi's national security on the investment climate. This is evidenced by the effect of the T-Value of $3.07(>1.96)$. It shows that the investment climate is directly affected by national security. It also shows that the security level of 21 regencies / 3 municipalities reflects the absence of a sense of fear and anxiety about the possibility of threats to the soul, property, and honor. If an area is considered to be safe, it will increase investment in Regency / City area in South Sulawesi Province, considering that Investors will invest in South Sulawesi which is safe and far from conflicts that can disrupt their business processes of.

\section{CONCLUSION}

This study examines the effect of National Security on Investment Climate mediated by the Consumer Confidence Index. This study uses the analysis of Structural Equation Model (SEM). The research findings indicated that National Security has a direct effect on the Investment Climate with a value of $t=3.07(>1.96)$. Meanwhile, the correlation between National Security and Consumer Confidence Index is significant with a value of $t=4.35$ 
$(>1.96)$. Then, the correlation between the Consumer Confidence Index and Investment Climate is also significant with the value $t=2.51(>1.96)$. The level of security of a Regency / City in South Sulawesi reflects the absence of a sense of fear and anxiety about the possibility of threats to the soul, property, and honor. If an area is considered to be safe, then it will increase investment in that district / city because investors will invest in areas that are safe and far from prone to conflict, so it will not interfere with their business processes.

The research problem stating whether there is an effect of National Security on the Regional Investment Climate, the research findings showed that National Security has an effect on the Investment Climate in South Sulawesi. Meanwhile, the research problem stating whether there is an effect of National Security on the Consumer Confidence Index, the research findings showed that National Security has an effect on the Consumer Confidence Index. Then, the research problem stating whether there is an effect of National Security on Investment Climate mediated by Consumer Confidence Index, the research findings showed that National Security has an effect on the Investment Climate in South Sulawesi that is mediated by the Consumer Confidence Index.

\section{SUGGESTIONS}

Based on the above conclusions, the following suggestions might be applied so that the research findings will provide optimal benefits for the research object:

This study has a limited number of secondary data and areas to be used as the research object so that research using qualitative methodology needs to be conducted to provide more detail findings in measuring the effect of the level of security in South Sulawesi on investment activity.

Further research can be conducted on the research object with a wider coverage area.

Local governments must be able to partner well with security forces to maintain the security of territorial areas in order to increase investor confidence in making investment in the area.

The increased investment in the South Sulawesi region can be implemented through a program to increase consumer confidence. Mediation of consumer confidence in investment is very important because a safe area cannot be a benchmark for increasing investment. It still requires consumer confidence.

\section{REFERENCES}

1. Bandalos, D. L. (1993). Factors influencing cross-validation of confirmatory factor analysis models. Multivariate Behavioral Research, 28(3), 351-374.

2. Bax, L., Yu, L. M., Ikeda, N., Tsuruta, H., \& Moons, K. G. (2006). Development and validation of MIX: comprehensive free software for meta-analysis of causal research data. BMC medical research methodology, 6(1), 50.

3. Bowen, N. K., \& Guo, S. (2011). Structural equation modeling. Oxford University Press.

4. Browne, M. W., \& Cudeck, R. (1992). Alternative ways of assessing model fit. Sociological methods \& research, 21(2), 230-258.

5. Cheung, G. W., \& Rensvold, R. B. (2002). Evaluating goodness-of-fit indexes for testing measurement invariance. Structural equation modeling, 9(2), 233-255.

6. Ghozali, I., \& Fuad, M. (2005). Structural equation modeling. Badan Penerbit Universitas Diponegoro, Semarang.

7. Hair Jr, J. F., Wolfinbarger, M., Money, A. H., Samouel, P., \& Page, M. J. (2015). Essentials of business research methods. Routledge.

8. Hu, L. T., Bentler, P. M., \& Hoyle, R. H. (1995). Structural equation modeling: Concepts, issues, and applications. Evaluating model fit, 76-99.

9. Huitt, W. (2004). Maslow's hierarchy of needs. Educational psychology interactive.

10. Jöreskog, K. G., \& Sörbom, D. (2003). LISREL 8.54. Structural equation modeling with the Simplis command language. 
11. Kelley, K., \& Lai, K. (2011). Accuracy in parameter estimation for the root mean square error of approximation: Sample size planning for narrow confidence intervals. Multivariate Behavioral Research, 46(1), 1-32.

12. Lancaster, H. O., \& Seneta, E. (2005). Chi-square distribution. Encyclopedia of biostatistics, 2.

13. MacKinnon, D. P., Fairchild, A. J., \& Fritz, M. S. (2007). Mediation analysis. Annu. Rev. Psychol., 58, 593-614.

14. McLeod, S. (2007). Maslow's hierarchy of needs. Simply Psychology, 1.

15. Schreiber, J. B., Nora, A., Stage, F. K., Barlow, E. A., \& King, J. (2006). Reporting structural equation modeling and confirmatory factor analysis results: A review. The Journal of educational research, 99(6), 323-338.

16. Siguaw, J. A. (2000). Introducing Lisrel: A guide for the uninitiated. Sage.

17. Steiger, J. H. (1990). Structural model evaluation and modification: An interval estimation approach. Multivariate behavioral research, 25(2), 173-180.

18. Tenenhaus, M., Amato, S., \& Esposito Vinzi, V. (2004, June). A global goodness-of-fit index for PLS structural equation modelling. In Proceedings of the XLII SIS scientific meeting (Vol. 1, pp. 739-742).

19. Thompson, B. (2004). Exploratory and confirmatory factor analysis: Understanding concepts and applications. American Psychological Association. 